\title{
Usability and Sociability of Direct Democracy Projects Based on Online Groups
}

\author{
Andrea Hrčková
}

Department of Library and Information Science, Faculty of Arts, Comenius University in Bratislava, Šafárikovo námestie 6, Bratislava, Slovak Republic, andrea.hrckova@uniba.sk

Abstract: Digital media, in particular social media, are often perceived to be changing political participation. In this discourse, the Internet is seen as a new public sphere with promises of increased democratization and access to political information. The younger generation in particular is supposed to have become more politically active thanks to the Web. In this article, the psychological, sociological and technological factors influencing the deliberative participation in virtual communities are being explored to understand some of the reasons for active or passive participation in e-democracy projects based in online groups. Some examples of successful edemocracy activities in Brazil, Germany and Slovakia are also discussed. Finally, the chances for sustainable development of direct democracy projects with the help of new media are presented.

Keywords: e-democracy, discussion groups, heuristic evaluation, usability, sociability, information architecture

Acknowledgement: This article was supported by APVV HIBER 15-0508.

\section{Introduction: E-democracy and E-government}

The Internet provides opportunities for citizens to engage with political institutions in several ways. E-democracy involves utilizing information and communication technologies to enable citizens to participate in democratic processes directly. These processes may involve creating laws, discussing the problematic aspects of public issues or participating in the development of effective state administration by expressing opinions and comments. Defining an exact boundary between e-democracy and e-government is difficult. Some scholars believe that e-government and e-democracy join together in order to create e-democracy (Clift, 2004). Heeks (2008) defines e-government as the use of information and communication technologies to improve the activities of public sector organizations, public services for citizens, entrepreneurs and society as a whole. Based on these definitions, e-government is understood as services created by government for citizens to streamline communication between themselves and government in various life situations including e-democracy. E-democracy projects can be created by government but also by non-profit organizations to streamline political decisions. In an ideal case, political participation is a two-way process that involves not 
only citizens' willingness to participate, but also the openness of politicians and governments to citizens' input (Rossini, Oliveira, 2016)

\section{The hindrances of e-democracy implementation}

The opinions on the feasibility of ideal e-democracy vary. In order to explore it, it is necessary to find the salient points in various forms of e-participations. The first challenge in introducing e-democracy for every citizen lies in technology. In western countries Internet coverage is not an issue anymore, and the introduction of drones should mitigate this problem in developing countries too. Still, different levels of technological literacy hinder a significant number of citizens from participating in the bottom to top decision-making process. In dictatorships we can still talk about a digital divide between these countries and the rest of the world.

Secondly, Bohman (2004) states that the central features of the Internet undermine the sort of political interaction that is required for genuine democratic deliberation. We side with this argument; the average person is in the main a heavy user of the biggest players on the Internet - mostly Google and Facebook. Specialized portals (such as e-democracy projects)also serve citizens that are interested in political events outside the online world. The Internet just makes this access less time and energy consuming.

The third hindrance for e-democracy projects is the prevailing lurking behavior of new media users. Smith (1992) states that $50 \%$ of the messages in online groups were written by $1 \%$ of the population. Hartz-Karp and Sullivan (2014) also point out a lack of interest, skills, and motivation of average citizens to participate, due to their information and transaction costs. Bastick (2017) adds that too much time/resource? is spent on filtering information rather than accessing new information. Few are interested enough to make citizens a feasible means of policy making.

Although online and offline environments are interlinked and the social norms in both types of communities are similar, the behavior of users in these environments may differ. A common ground for this effect is called the disinhibition effect (Bocij, 2004). The disinhibition effect is a change in patterns of personality behavior because of the "anonymity" of Internet. The consequence is a higher level of openness and detachment. Suler (2004) postulates that this effect happens due to 6 factors: dissociative anonymity ("They'll never know who I really am"), invisibility ("We can't see each other online"), asynchronicity ("I can always leave my message behind without consequence"), solipsistic introjection ("This is how I see you, in my mind"), dissociative imagination ("My online persona is different from who I am in real life"), and minimization of authority ("I can do whatever I want online"). The Internet blurs boundaries that keep our behavior in check in real life. The absence of social context and face-to-face interactions increase the level of openness but also the probability of conflicts, criticism, bullying and deviations such as flaming, trolling and deindividualization.

Deindividualization is a suppression of the personality characteristics of the participant for the sake of a group. The individual automatically adopts the values and standards of the group, which is particularly dangerous in extremist groups and leads to antisocial behavior (Bocij, 2004). Social media, mainly social networks, tend to support identification with the social group. According to 
Macek (2013), the production of content in social media could be seen as an exposure of taste, and is partly motivated by a will to conform (i.e., by a need to ensure that I do not differ in taste and opinions from "our" people). This is particularly valid for social networks, as opposed to discussion groups or wikis that are gathered around topics of interest rather than around people in the network.

The research of Del Vicario et al. (2016) showed that people in social networks tend to seek interaction with like-minded individuals and limit themselves to so called echo chambers, where they confirm their ideas and where their opinions bounce back like an echo. This fosters extreme views and disinformation as individuals are more supported within their own communities. According to Wojcieszak and Mutz (2009) intolerance can be found more in like-minded online communities and respect for diverse views is visible in more heterogeneous environments. The algorithm of Facebook in particular contributes to echo chambers, as it disproportionately shows content and people that are similar to previously expressed preferences.

The theory of selective exposure also confirms that people tend to accept information that supports their opinions and to avoid information that is in contradiction with them. This theory is a precondition for creating filter bubbles in social media. Filter bubbles are the result of personalization according to the location and preferences of the user, learnt from previous interactions in search engines or social networks. According to Pariser (2011) this filtered information in an online environment tends to confirm the views of the person, close her or him into her or his own culture and ideological bubbles and isolate him from different opinions and topics. This creates a culture of "showing and yelling" rather than listening and deliberative discourse (Bastick, 2017). Others (as Stetka, Mazák, 2014) criticize these platforms also for facilitating 'slacktivism' - activities in support of a cause that have little effect other than making the person feel good about themselves for having contributed to the cause (e.g. 'liking' on Facebook).

The focus on people rather than content and phenomena such as filter bubbles and echo chambers are the factors that contribute to our strong skepticism about whether social networks are appropriate tools for e-democracy. It may appear that politicians are closer to citizens by communicating with them on Facebook. But isn't this communication more about presenting themselves, rather than engaging citizens in democracy processes and trying to find solutions for particular problems? Moreover, high-level politicians hire marketing agencies to communicate with citizens, so the interaction is deceptive. Admittedly, social networks fostered revolutions in the countries where the standard of living had fallen significantly. Despite this, they never served as a mediator for constructive discussion, consensus and resolution of problems.

Bastick (2017) argues that the e-democracy projects didn't contribute to the revolution of democratic systems as expected. The processes remain untouched, while e-democracy was normalized for the offline world and current political system. These statements can be backed up by the examples of Slovak projects Znasichdani or Datanest that inform about the exorbitant spending of public finances, but the general public still doesn't have control over the process. Participatory budgets in Brazil or some cities such as Trnava and some city districts of Bratislava empower citizens to take part in the decision process for budget division without a mediator (representative). Still it never involves the whole budget of the city, just a part. 
Another bottom to top approach is presented in a Slovak project sk.e-demokratia, which is intended to establish a political party from the general public just based on the natural selection of leaders in the discussions within discussion groups. Its candidates should therefore consist of professionals only and the idea is the creation and promotion of a party without the need for sponsors and money for campaigns to fund becoming a representative. As such, the aim of the project is to tackle "democracy responsive to its funders" or money-based democracy, as Lessig (2015) names it. Although the success of this project is possible as the general public is frustrated by overwhelming corruption in the politics in the country, the lack of motivation is visible from the small number of participants and contributions. Our hypothesis is that the gains are still fewer than losses on this platform.

We side with Wright's (2012) argument that the revolutionary and democratic potential lies in how technologies are designed and adopted by humans in particular social and political contexts. The political benefits of the Internet are a combination of affordances that technology provides and the unexpected ways that people can make use of them (Rossini, Oliveira, 2016).

\section{E-democracy in Brazil as an example of best practice}

This argument was supported by the successful example of the Brazilian E-democracia portal. The political reform in 2013 that took place after nationwide uprisings resulted in Brazil being among the top countries investing in democratic innovations (Rossini, Oliveira, 2016). Portal EDemocracia is an initiative of the House of Representatives that invited citizens to participate in and comment on lawmaking issues through wiki and discussions about the sensitive topics that caused the uprising, and the discussions were structured accordingly. As a result, 150,000 people participated in the online discussions of the topics in two years. This success can also be explained by the fact that the portal E-Democracia was the only option for many Brazilians who would not be able to take part in public hearings to participate in this debate.

The parliamentary committee held public hearings with members of civil society and professionals. Citizens could also participate through comments and suggestions on Portal E-Democracia. During the public hearings in Congress, representatives brought questions and comments from the online debates to the discussion. The House of Representatives presented the final report on the political reform in 2015. Although citizens' inputs had no clear connection with political outcomes and the agenda was primarily selected by Congress members and staff; the platform provided citizens with a variety of features that enabled them to engage with policy decisions.

Congress pointed out the high relevance of the discussion. Content analysis of 3,043 messages showed that debates were characterized by real dialogical interactions (not simply sharing their views and talking past one another) in the majority of posts (84.7\%). Results demonstrated a substantial indication of heterogeneity, as people explicitly disagreed with others in $48.8 \%$ of the analyzed messages, whereas agreement was observed in $43.1 \%$ of the cases. Even almost a quarter of those who revealed disagreement, were willing to negotiate with those with contrasting ideas. The discussion was also characterized by low levels of disrespect in the form of personal offense and irony $(3.1 \%)$ or rudeness to disqualify other people or arguments $(2.9 \%)$. Only $2.9 \%$ of the analyzed 
messages were completely off-topic. The only problem spotted was that the majority of messages weren't backed by external sources. This was the case for $66.4 \%$ of the sample (Rossini, Oliveira, 2016).

Nowadays the portal still consists of forums for citizens to engage with parliament, wikis for lawmaking and engagement features such as polls and chat. The discussions are divided according to the topics (politics, health, sport, education, communication and providence). Wikis are also divided according to the topics. The author is not anonymous, modifications are transparent and the interface allows voting.

\section{Socio - psychological factors affecting deliberative discussion}

The results of Rossini, Oliveira (2016) point out that constructive discussion based on deliberation is possible in e-democracy. Deliberation can be understood as the activity of listening and giving reasons to build a collective consensus about a controversial issue. From Habermas' perspective, deliberation is a communicative process that requires participants to mutually recognize each other as equals, to respect different points of view and to exchange reasonable and justified arguments to reach a consensus about a common public issue. The normative criteria for deliberation includes freedom from political and economic coercion; inclusion of everyone affected by the decision; and the consideration of others' arguments and willingness to cooperate in the decision-making process (Dahlberg, 2004). Some researchers question whether deliberation is feasible in virtual communities. O'Keefe (2008) mentions three topics that are very sensitive in terms of constructive discussions and administrators should be vigilant and aware of them: politics, religion and internet browsers.

According to Iandoli, Klein and Zollo (2008), in order for virtual communities to work properly, stakeholders must be able to attract and retain a critical mass of users, provide them with support and incentives for deliberation, and rules and processes for effective communication. The main social aspects, discussed in this article, which may affect the construction of political platforms and discussion, are social and personal identity, a sense of belonging, and various aspects of social capital that can be fostered by information architecture and the sociability of the interface.

Social capital is defined as the "sum of actual and potential resources embedded within and derived from the network of relationships possessed by an individual or social unit. Social capital comprises both resources within the network and the asset that may be mobilized through that network" (Sun, 2009, p. 142). Social capital is intangible and can be seen as illiquid goods based on relationships. It is transferred in the hope that it may bring benefits to both the owner recipient. The balance between gaining and losing in terms of giving time and energy to these virtual relationships has to be preserved.

Social capital has been associated with lower levels of deviances in communities and higher probability of sharing information and discussion. Social capital depends on many aspects, one of the most important is trust. Trust leads directly to cooperative behavior among exchange partners because of the belief that the other party will not act opportunistically (Tung et al., 2001). Social capital is best created in communities where participants share the same values, but paradoxically are diverse in character. The emotional aspects of a sense of belonging to the group, a will to participate 
or collaborate on something, and feeling of reciprocity also has to be present. (Boeck, Fleming, Kemshall, 2006).

In the context of e-democracy the sense of belonging and identity is strongly manifested, when members participate in local decisions (of the city, or its parts where they come from). This could be seen on the Demos project in Hamburg, where the strategic vision for the development of the city was prepared with the citizens, and the quality of debate was high. Another good and successful example is from Slovakia. "Odkaz pre starostu" (Message for Mayor) is an application where citizens report small issues regarding their city. It is indirectly connected to the local government with the help of an NGO and is widely used by citizens. Many local issues that would otherwise be overlooked were resolved through this platform in Bratislava.

Social identification is one of the foundations for social movements. Identification with the group also leads to a greater commitment and a lower probability of leaving the group, even if it has a low status. Having a particular social identity means being at one with a certain community, being like others in the group and seeing things from the group's perspective. Having a particular role identity means acting to fulfill the expectations of the role, coordinating the interaction with partners and manipulating the environment to control the resources that one is responsible for (Stets, Burke, 2000).

Social identity is created by the shared values of members and is represented by the information and emotions they participate in. It involves the fact that people group themselves according to common behavior or characteristics, perceive oneness with the group and compare their beliefs and attitudes to other members. Creating a common identity leads to common behavior and develops cohesiveness within a group of people who may not even like each other (Tung et al., 2001).

Personal identity is visible in the profile and the role that is usually assigned according to the activities in virtual communities. On one side, anonymity may encourage minorities to participate by removing constraints, on the other, identity tends to foster sincerity, civility, and rationality and therefore is preferable to foster deliberation (Janssen \& Kies, 2005). The member constructs his identity and reputation in virtual communities by providing content. As such, influence or respect is built in addition to his real social role and this personal gain and recognition is a stimulating factor in active participation (Moore, Serva 2007).

\section{Information architecture of online e-democracy groups}

Wright and Street (2007) argue that the design of an interface plays a significant role in the success of e-democracy and call for more research. The interface features that are being considered for smooth and engaging conversation in e-democracy projects in this article, are based on four basic pillars of website information architecture: usability, accessibility, credibility and findability and a fifth pillar identified in the case of virtual communities by Preece and Maloney-Krichmar (2003) sociability.

Sociability is concerned with developing social policies and supporting social interaction of people with the help of technology, rules and processes. Knowing and supporting people with different 
individual needs and balancing them with the needs of the community is one of the key components of sociability in virtual communities. The other components of sociability are purpose, rules and support of dialogue and interaction (Preece, Maloney-Krichmar, 2003).

The purpose or common interest and need of the community provides a reason for individuals to be a part of a group. It needs to be unique and clear - graphics shouldn't distract attention from the purpose (Preece, Maloney-Krichmar, 2003). In the context of e-democracy, the most important purpose is in enabling citizens to actually influence political decision making. The direct connection to formal political structures is more likely to produce external outcomes. Kies (2010) found in his comparative research that the initiatives connected to formal structures are more likely to foster citizen deliberation.

The interaction of members around the common goals of a group is guided by rules and norms. Rules are formal or informal protocols of the group that also serve to prevent deviations in conversations. In this sense, the role of the moderator is crucial - still, the most respected rules in virtual communities are developed together by the members and not imposed by authority. Interactive moderation is seen as a positive design choice, as censoring content constrains participation (Rossini, Oliveira, 2016). The moderator tends to fulfill more functions besides filtering the discussion; he has a crucial role in supporting dialogue and interaction by facilitating and leading communication so that the discussion is focused and the content current. People also need to be reminded of the group from time to time so that they don't forget to return.

Smooth dialogue and interaction depends largely on trust. Trust depends on many psychological aspects that are not easy to influence - mainly the trustfulness of the recipient and the credibility of the communicator. In a virtual environment, the credibility of the interface can be supported by disclosure of information about the ownership of communities and about the manipulation of the information of members. However, trust in the virtual environment is mostly influenced by the aesthetics and topicality of the design interface (Fogg, 2014).

Besides aesthetics, the usability of the interface is important to consider so that the transaction costs for participants are as low as possible. Basic features of online communities such as registration, publishing, categorizing, editing, reading and navigating content need to be as intuitive, memorable and as least time consuming as possible. Some discussion groups are very sensitive about the wrong categorization of content and arguments can be prevented by correct information architecture.

In the context of e-democracy, it needs to be noted that initiatives that are too broad and attempt to host large-scale discussions face difficulties in engaging the public in purposeful debates. Forums that are structured around specific political issues tend to produce better outcomes, especially when linked to policy formation and decision-making as they are easy to identify with (Coleman, Moss, 2013).

E-democracy is often criticized as a platform for providing political discussion to those who are already involved in political discussion - mostly to educated middle-class white men. Involving all kinds of users, including disabled people, requires respecting accessibility standards and guidelines. 
For example, visually-impaired users encounter problems contributing to forums with non-standard forms that have too many icons, requiring them to skip with their readers. Reading unstructured discussions in code is also cumbersome (Zehe, 2009). Accessibility for different devices (such as mobile phones) or robots (for findability of the forum) should also be considered, in order to involve as many users as possible. Findability depends on many attributes of the site, e.g. the number of links pointing to the website and the public availability of all posts.

\section{Heuristic evaluation indicators for e-democracy projects based on online groups}

The aforementioned socio-psychological and technological factors influencing the engagement of online group members are summarized in table 1 . These factors can also be considered as indicators for heuristic evaluation of e-democracy projects, as they were used to assess the information architecture and sociablity of virtual groups in general (Hrčková 2013). In this research, the preferences of users in terms of credibility, usability and sociability of online groups were validated by surveying 161 users of 33 different discussion groups.

Heuristic evaluation is a critical assessment of certain functions of the system by advanced users (Nielsen, Molich 1990). Its purpose is to find interface design problems that could prevent users from finding critical information. Three to five evaluators are sufficient to perform heuristic evaluation as they find the majority of shortcomings. More evaluators produce redundant results in simpler systems (Nielsen and Molich 1990). Interface evaluation is based on pre-defined criteria (indicators) that reflect a perfect state of the interface.

Table 1: Indicators for heuristic evaluation of the interface of online groups

\section{Credibility}

Design topicality. Information availability and visibility about the owners. Possibility to rate the contributions and visibility of the most rated contributions. The need for registration.

Clear rules and sanctions. The availability of information about author's background.

\section{Usability}

Ease of use of the basic functions of the interface: registration, signing in/out, contributing to the right topic, browsing and searching (by author, topic and date). Utilization of the language of users. Availability of help.

\section{Findability}

The authority of domain. Number of offpage links. Public availability and archive of posts. Metadata and semantic tags. Speed of the website.

\section{Accessibility}


Text alternative to important images including captcha. Simple form for contributions without redundant icons. Division of contributions (according to headings, not frames). Absence of fast flashing or pop-ups (especially advertisements). Responsive design/ application for mobile devices.

\section{Sociability}

Clear purpose and visual identity. Support of dialogue and interaction through appropriate moderation, stable server, absolute power over own contributions. Support of identity of members by the availability of profile and roles. Support of sense of belonging by narrow e.g. local topics, supporting collective identity through special activities or possibilities for users.

According to the analysis of literature, just one special indicator would be needed, to be included in a heuristic evaluation of e-democracy projects: the connection of e-democracy portal with formal structures.

\section{Conclusions and further development of e-democracy projects based on new media}

This article has sought to move forward the debate about the social or technical determinism of e-democracy initiatives. The success of e-democracy as well as democracy is based largely on people and their motivation and interest to be involved in socio-political issues. The motivation for collective goods (e.g. to solve problems in society or to build something together) is complemented by individual motivations to contribute to any kind of communities that build social capital and social identity, or to experience a sense of belonging to a group. In the context of e-democracy a connection to formal structures to actually change something needs to be present. A critical mass will contribute to e-democracy discussions, if the discussion is lively and active. This could be achieved by involving leaders but also runs the risk of attracting extremists. However, virtual communities also have self-regulative mechanisms that serve as stimulators for deliberation, if the collective culture is present.

In terms of technology, the active contribution to e-democracy based on online groups could be supported or hindered by the design and information architecture of interfaces that serve as public spaces for interaction. The balance between gaining and losing in terms of giving time and energy to a virtual group also needs to be preserved. We side with the argument that technologies alone cannot solve democratic shortfalls. Still, technologies may enable and simplify or vice versa, decelerate the process.

Although e- democracy has many advantages for society, the total replacement of democracy procedures by e-democracy, liquid democracy or blockchain democracy is justifiably connected with the fear of trading with votes, security infringements and the inclination to choose popular candidates because of a lack of time and interest (as is also true in representative democracy). Moreover, the major problem with direct voting for decision making is that paradoxically, direct democracy cannot defend minorities and thus it supports only the opinions of the majority. If Plato defined democracy as the rule of rabble, direct democracy would be the rule of average. 
The average population would require an extensive investment of time to be educated about various fields of interest in order to make competent decisions. These revolutionary changes would require the willingness of government and systematic changes (mainly in the field of education) to take place. The problem is, systematic changes are unpopular in current politics. E-democracy initiatives could be therefore seen rather as complement to, not as a replacement of, democracy.

\section{References}

Bastick, Z. (2017) Digital Limits of Government: The Failure of E-Democracy. Beyond Bureaucracy. Public Administration and Information Technology, 25. Springer. Retrieved from https://doi.org/10.1007/978-3-31954142-6_1

Bocij, P. (2004). Cyberstalking: Harassement in the Internet Age and how to Protect your Family. Praeger.

Bohman, J. (2004). Expanding dialogue: The Internet, the public sphere and prospects for transnational democracy. The Sociological Review, 52, p. 131-155. doi:10.1111/j.1467-954X.2004.00477.x

Boeck, T., Fleming, J., Kemshall, H. (2006). The Context of Risk Decisions: Does Social Capital Make a Difference? Forum: Qualitative social research, 7, 1. Retrieved from http://www.qualitative-research.net/index.php/fqs/article/view/55/113

Clift, S. (2004). E-democracy, e-governance and public network. Open Source Jahrbuch. Retrieved from http://www.opensourcejahrbuch.de/download/jb2004/chapter_04/IV-5-Clift.pdf

Coleman, S.; Moss, G (2012). Under Construction: The Field of Online Deliberation Research. Journal of Technology $\mathcal{E}$ Politics, $9,1$.

Dahlberg, L (2004). Net-public sphere research: beyond the "first phase". Javnost - The Public, 11, 1. Retrieved from http://javnost-thepublic.org/article/2004/1/2/

Edemocracia. Retrieved January 30, 2018, from https://edemocracia.camara.leg.br/home

Fogg at al. (2014). How do People Evaluate a Website's Credibility? Stanford: Persuasive Technology Lab. Retrieved from https://dejanseo.com.au/media/pdf/credibility-online.pdf

Gonçalves da Conceição Rossini, P., \& Veiga de Oliveira, V. (2016). E-Democracy and Collaborative Lawmaking: The Discussion of the Political Reform in Brazil. International Journal Of Communication, 10, 21. Retrieved from http:// paperroom.ipsa.org/papers/paper_36306.pdf

Hartz-Karp, Janette and Sullivan, Brian (2014) The Unfulfilled Promise of Online Deliberation. Journal of Public Deliberation, 10, 1. Retrieved from https://www.publicdeliberation.net/jpd/vol10/iss1/art16

Heeks, R. (2008, October 19). What is eGovernment? Retrieved November 30, 2017, from http://www.egov4dev.org/success/definitions.shtml

Hrčková, A. (2013). Heuristic Evaluation Metrics for the Interfaces of Discussion Groups (poster). Copenhagen: Colis, 2013.

Iandoli, L., Klein, M., and Zollo, G. (2008). Can We Exploit Collective Intelligence for Collaborative Deliberation? The Case of the Climate Change Collaboratorium. MIT Sloan Research Paper, 4675-08. 
Janssen, D., Kies, R. (2004). Online Forums and Deliberative Democracy: Hypotheses, Variables and Methodologies. Conference on Empirical Approaches to Deliberative Politics. Florence: European University Institute.

Kies, R (2010). Promises and limits of Web-deliberation. New York: Palgrave Macmillan.

Lessig, L. (2015). Our democracy no longer represents the people. Here's how we fix it. Live performance in TEDx MidAtlantic. Retrieved from https://www.youtube.com/watch?v=PJy8vTu66tE

Macek, J. (2015). Social Media and Diffused Participation. In Living in the Digital Age. Brno: Masarykova univerzita. Retrieved from https://www.researchgate.net/profile/Anna_Sevcikova/publication/279572823_The_Educational_Dimension_of_Pornography_Adolescents'_Use_of_New_Media_for_Sexual_Purposes/links/5596f00e08ae99aa62c8c7d1.pdf\#page=165.

Moore, T. D., \& Serva, M. A. (2007). Understanding member motivation for contributing to different types of virtual communities. Proceedings of the 2007 ACM SIGMIS CPR conference on 2007 computer personnel doctoral consortium and research conference The global information technology workforce - SIGMIS-CPR 07. doi:10.1145/1235000.1235035

Nielsen, J., Molich, R. (1990). Heuristic Evaluation of User Interfaces. CHI '90 Proceedings. NY: ACM

Odkaz pre starostu - Bratislava. Retrieved January 30, 2018, from https:/ /www.odkazprestarostu.sk/

O'Keefe, P. (2008). Managing online forums: everything you need to know to create and run successful community discussion boards. New York, NY: AMACOM.

Pariser, E. (2012). The filter bubble: what the Internet is hiding from you. London, England: Penguin Books.

Preece, J., Maloney-Krichmar, D. (2003). Online Communities: Focusing on sociability and usability. Handbook of Human-Computer Interaction. Mahwah: NJ.

Smith, M. A. (1992). Voices from the WELL: the logic of the virtual commons [Pdf]. Los Angeles: U.C.L.A. Retrieved from http://dlc.dlib.indiana.edu/dlc/bitstream/han-

dle/10535/4363/Voices_from_the_WELL.pdf?sequence $=1 \&$ isAllowed $=y$

Štětka, V., \& Mazák, J. (2014). Whither slacktivism? Political engagement and social media use in the 2013 Czech Parliamentary elections. Cyberpsychology: Journal of Psychosocial Research on Cyberspace, 8(3). doi:10.5817/cp2014-3-7

Stets, Jan E., Burke, Peter J. (2000). Identity Theory and Social Identity Theory. Social Psychology Quarterly, 63, 3. Retrieved from http://www.jstor.org/discover $/ 10.2307 / 2695870$ ?uid=3739024\&uid=2134\&uid=2\&uid=70\&uid=4\&sid=21101737209357

Suler, J. (2004). The Online Disinhibition Effect. Cyberpsychology and behavior, 7, 3.

Sun, Szu-Yuan, et al. (2009). Influence on Willingness of Virtual Community's Knowledge Sharing: Based on Social Capital Theory and Habitual Domain. Proceedings of world academy of science, engineering and technology, 41. p. 142-149.

Tung, Lai, et al. (2001). An Empirical Investigation of Virtual Communities and Trust. Proceedings International Conference on Information Systems. Retrieved from http://aisel.aisnet.org/cgi/viewcontent.cgi?article $=1114 \&$ context $=$ icis 2001 
Vicario, M. D., Vivaldo, G., Bessi, A., Zollo, F., Scala, A., Caldarelli, G., \& Quattrociocchi, W. (2016). Echo Chambers: Emotional Contagion and Group Polarization on Facebook. Scientific Reports, 6, 1. doi:10.1038/srep37825

Wojcieszak, M.; Mutz, D. (2009). Online Groups and Political Discourse: Do Online Discussion Spaces Facilitate Exposure to Political Disagreement? Journal of Communication, 59, 1

Wright, S., \& Street, J. (2007). Democracy, deliberation and design: the case of online discussion forums. New Media \& Society, 9(5), 849-869. doi:10.1177/1461444807081230

Zehe, M. (2009). Why are web forums so unpopular with the blindness community? Retrieved from: http://www.marcozehe.de/2009/04/07/why-are-web-forums-so-unpopular-with-the-blindness-community/

\section{About the Author}

Andrea Hrčková, PhD. is a research assistant at the Department of Library and Information Science, Faculty of Arts, Comenius University in Bratislava. Her specializations include new media, search engine optimization, information organization and information retrieval. She was one of the founding members of an edemocracy initiative in Slovakia. 